\title{
Correction to: Evaluating the Urban Quality Through a Hybrid Approach: Application in the Milan (Italy) City Area
}

\author{
Alessandra Oppio (D), Marta Bottero (D), Federico Dell'Anna (D), \\ Marta Dell'Ovo (D), and Laura Gabrielli (D)
}

Correction to:

Chapter "Evaluating the Urban Quality Through a Hybrid Approach: Application in the Milan (Italy) City Area" in: O. Gervasi et al. (Eds.): Computational Science and Its Applications - ICCSA 2020, LNCS 12253, https://doi.org/10.1007/978-3-030-58814-4_21

In the version of this paper that was originally published the names and surnames of the authors have been inverted.These are now corrected as following:

Alessandra Oppio

Marta Bottero

Federico Dell'Anna

Marta Dell'Ovo

Laura Gabrielli 